Kennesaw State University

DigitalCommons@Kennesaw State University

Faculty Publications

$3-1994$

\title{
Influence of Family Relationships on Succession Planning and Training: The Importance of Mediating Factors
}

Ivan Lansberg

Lansberg Associates

Joseph H. Astrachan

Kennesaw State University, jastrach@kennesaw.edu

Follow this and additional works at: https://digitalcommons.kennesaw.edu/facpubs

Part of the Business Administration, Management, and Operations Commons, and the Entrepreneurial and Small Business Operations Commons

\section{Recommended Citation}

Lansberg, Ivan, and Joseph H. Astrachan. "Influence of Family Relationships on Succession Planning and Training: The Importance of Mediating Factors." Family Business Review 7.1 (1994): 39-59. Print.

This Article is brought to you for free and open access by DigitalCommons@Kennesaw State University. It has been accepted for inclusion in Faculty Publications by an authorized administrator of DigitalCommons@Kennesaw State University. For more information, please contact 


\title{
Influence of Family Relationships on Succession Planning and Training: The Importance of Mediating Factors
}

\author{
Ivan Lansberg, Joseph H. Astrachan
}

This study models the influence of family relationships on succession variables, using a sample of 130 participants from 109 family businesses. Results suggest that the effects of family adaptability and family cohesion on succession planning and successor training are determined by the family's commitment to the business and the quality of the ownermanager and successor relationship. The study finds that the influence of family relationships on administrative behavior in family businesses is not always direct, as was previously assumed, but is mediated by various factors.

Over the last decade, researchers have increased their attention to the impact of family relationships on family businesses (Dyer, 1986; Ward, 1987) and the differences between family and non-family controlled businesses (Astrachan, $\&$ Astrachan, 1993; Donnelly, 1964). For example, Dyer (1986) found that family culture has a lasting impact on the culture of family businesses. (He is not explicit about the mechanisms through which family and organizational culture interact.) By family business we mean a company that is owned or controlled by a family and in which one or more relatives is involved with management. It has been estimated that 80 percent of all firms in the U.S. economy conform to this definition (Zeitlin, 1976).

Note: The authors gratefully acknowledge the assistance of Sharon Rogolsky, Roderick Correll, Erika Morgan, Barbara Butler, and Cathy O'Keefe for their contributions to the development and implementation of this study, and Clayton Alderfer, Paul DiMaggio, Kelin Gersick, Madeline Heilman, Edith Perrow, John Ward, and multiple anonymous reviewers for their helpful comments on earlier versions of this paper. 


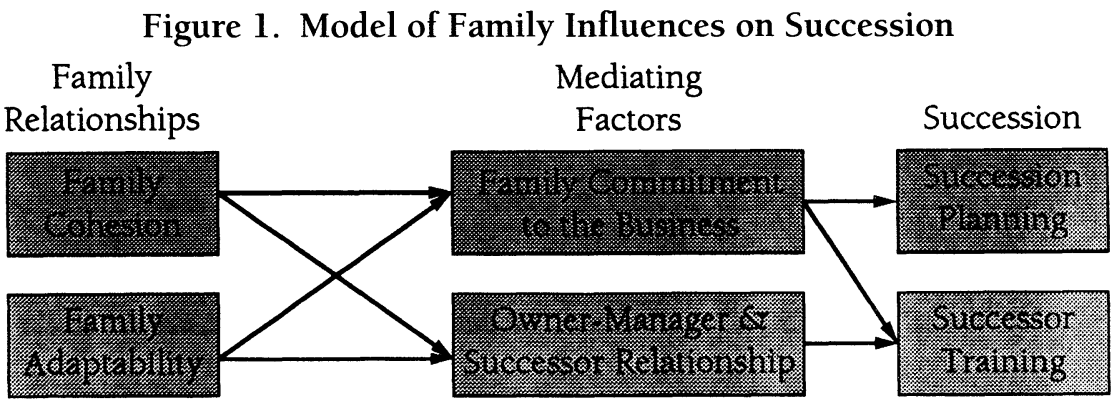

For the most part, prior theory and research conceptualizes the family and firm in broad systemic terms (Miller \& Rice, 1967; Davis \& Stern, 1980; Kepner, 1983). Such approaches typically view the family and the business as two distinct and monolithic entities that directly influence each other. We believe that their mutual influence may be neither entirely direct nor simple. Rather, the effect of one system on the other is likely to be mediated by specific factors.

This study examines the relationship between specific family and organizational variables. Our focus is on the influence of family adaptability and family cohesion (Olson, Russell, \& Sprenkle, 1988) on management succession planning and successor training. (By successor we mean that individual who has been designated to be the next leader of the business.) We posit that the effects of family adaptability and family cohesion on management succession planning and successor training are mediated by the familys commitment to the business and the quality of the relationship between the owner-manager and successor. The hypothesized relationships among these variables are depicted in the model shown in Figure 1 . We shall first turn our attention to the dependent variables in the model.

\section{Succession in Family Businesses}

The scant research available suggests that family companies frequently avoid planning for succession and training a successor-often with grave consequences. In a qualitative study of fifty-nine businesses, Rosenblatt, de Mik, Anderson, and Johnson (1985) found that family business owners often resist succession planning and that this, in turn, diminishes the odds that the business will survive beyond the first generation. Using data from an earlier study of family companies by Christensen (1953), Trow (1961) found that businesses that had developed a succession plan and communicated it to critical stakeholders were more likely to remain profitable after succession than those that had failed to plan. In a study of 200 family businesses, Ward (1987) found that planning for succession and successor development were among the most important characteristics associated with businesses that were able to survive a generational transition. 
Many factors have been identified for why the lack of succession planning and successor training may lead to a family business's demise. The literature suggests that if planning and training are postponed, an owner-manager's death or incapacitation may suddenly deprive the family business of crucial managerial assets, including strategic information about markets, products, and employees; and critical connections with external stakeholders such as suppliers, clients, and financing sources (d'Amboise \& Muldowney, 1988; Hershon, 1975). The unexpected death of the owner-manager forces the owning family to fill a leadership vacuum in the business, while simultaneously contending with the disposition of the estate and mourning the loss of a beloved family member. The precise effects of these factors have yet to be studied in detail.

The influence of family relationships can both facilitate and hinder succession planning and successor training. Challenges generated by senior management succession are often complicated by family relationships and the transfer of ownership (Ward, 1987; Handler \& Kram, 1988). For example, Friedman (1991) suggests that when the choice of a successor from among the siblings is interpreted as parental favoritism, it can unleash dysfunctional rivalries among brothers and sisters that can delay and complicate the succession transition. On the other hand, in a study of forty family companies, Dyer (1986) found that collaborative families-families in which members are mutually supportive and work well together-are more likely to effectively transfer the business to the next generation. In a sample of fifty-eight businesses, Malone (1989) found that perceived family harmony positively affected the degree of business continuity planning. Similarly, Rosenblatt and others (1985) observed that because owning families are often in business for the long haul, they can develop successors from an early age (for example, with summer internships, after school work, and dinner conversation about the business).

When succession planning and successor training occur in these companies it is often informal, vague, and inexplicit. According to Lansberg (1988) and Ward (1987), succession planning should be explicit and should include the formulation of a viable vision of the company after succession, the development of criteria for selecting a successor, the creation of a plan for training successor candidates, and the design of structures appropriate for managing the change in the business as well as in the family, such as a board of directors and a family council. The training of a successor, on the other hand, should include early exposure to critical positions in the firm, formal education, related work experience outside the company, and extensive coaching and mentoring from the owner-manager and key senior executives.

\section{Family Relationships}

To better document the influence of family relationships on succession, this study sought to delineate specific family variables through the use of established measures from the field of family studies. The independent variables in this research 
were derived from concepts of family cohesion and family adaptability from the Circumplex Model of Family Relationships developed by Olson and his colleagues (1988). This model represents a synthesis of a number of influential theoretical approaches to the study of family relationships and has been extensively used in research. Olson (1988) found that high cohesion and adaptability are associated with healthier family relationships and effective communication.

Cohesion refers to the degree of connectedness and emotional bonding that family members experience within the family. According to Olson (1988), normal families range along this dimension from connected (high cohesion) to separated (low cohesion). Connected families have a collectivist orientation while simultaneously maintaining clear boundaries between subsystems of the family, for example, between parents and children. In these families, emotional closeness, intimacy, and loyalty are emphasized.

In separated families, members treasure their autonomy and feel that spending considerable time apart from the family is important. In these families an individualistic orientation predominates. However, separated families are not totally disengaged. They are willing to spend some time together and to participate in making critical joint decisions.

Family adaptability, the second dimension, refers to the ability of the family system to make internal changes in response to situational and developmental stress. Families range along this dimension from flexible (high adaptability) to structured (low adaptability). In flexible families, individuals modify rules and roles in accordance with external demands and developmental changes. In these families, leadership responsibilities are shared and members' input into family decisions is encouraged.

Structured families, in contrast, are those in which an authoritarian leader predominates. In these families rules are explicit and firmly enforced, and individual behavior tends to be restricted to specific roles. These families do not readily change rules, roles, and boundaries in response to external demands or developmental transitions.

\section{Factors Mediating the Influences of Family on Succession}

The family business literature suggests that family relationships play an important role in the extent to which management succession is planned (Ward, 1987; Davis \& Stern, 1980; Lansberg, 1988). This is one way in which family relationships influence the longevity and performance of family firms. The mechanisms that link specific family and succession variables have not previously been identified and studied. We maintain that the impact of family relationships on succession planning and successor training is largely mediated by two variables: the family's commitment to the business and the quality of the relationship between the owner-manager and successor. 
Family commitment refers to the degree to which the proprietary family is dedicated to involving the next generation of family members in the ownership or management of the company. Highly committed families view the firm as a continuing legacy in which the family's traditions, identity, and culture are embodied. A distinctive feature of families that are highly committed to their businesses is that the parents convey to their children a sense of excitement about the business and its future. Ensuring the long-term vitality of the firm is a central concern for these families (Poza, 1989). Such families are often willing to forgo personal benefit for long-term business prosperity. Moreover, these families are clear about the benefits that they are likely to derive from the company in the long run (Ward, 1987; Dyer, 1986).

In contrast, low-commitment families are those that are less concerned with business survival. Such families often keep an impervious distinction between the company and the family. There are at least two types of families in which this occurs. In one, the parents, who may have inherited the company, experience the business as an onerous burden from which they try to spare their children (cf. Correll, 1989). In the other type of family, the business is viewed as a precious possession that would be spoiled if given to the children. In either case, communication about the business within the family is discouraged, and the children are directed to pursue activities and careers outside.

The second mediator of the effect of family adaptability and family cohesion on succession planning and successor training is the quality of the relationship between the owner-manager and the successor. High-quality owner-manager and successor relationships are characterized by trust, mutual support, open and earnest communication, and a willingness of each party to acknowledge the other's achievements. It is also important that the ownermanager and successor be able to ask one another for help and guidance when needed, and that they share relevant information concerning the business, the family, and each other. Strong owner-manager and successor relationships often involve the sharing of interests and hobbies that are not related to the business.

In contrast, ineffective owner-manager-successor relationships are characterized by poor and infrequent communication, an unwillingness to directly explore differences of opinion, and the active withholding of important information, particularly regarding performance evaluation and expectations of competence. In troubled relationships there is a great deal of reliance on third parties for communication, especially regarding tension and conflict (Smith, 1989; Bowen, 1978).

As indicated previously, we posit that these variables mediate the influence of family cohesion and adaptability on succession planning and successor training. We next turn our attention to the specific relationships between these various factors. 


\section{A Model of Family Influences on Succession}

In this section we explain the relationships between the variables described above, depicted in Figure 1, and we introduce the specific hypotheses guiding this study. These hypotheses are subject to mutandis paribus assumptions, particularly with regard to such factors as the family's ethnicity (Woehrer, 1988), the owner-manager's style of departure from the firm (Sonnenfeld, 1988), the life stage of the owner-manager and the successor (Davis \& Tagiuri, 1989), the culture of the family and the firm (Schein, 1985; Astrachan, 1988), the stage of development of the company (Greiner, 1972; Hershon, 1975; Ward, 1987), and the size and performance of the company (d'Amboise \& Muldowney, 1988).

We shall present hypotheses concerning the influence of family cohesion and adaptability on the family's commitment to the business and the quality of the owner-manager and successor relationship-our mediating variables. We will then turn our attention to the influence of the mediating variables on succession planning and successor training-our dependent variables.

Effect of Family Cohesion and Adaptability on the Quality of the OwnerManager and Successor Relationship. We maintain that because the ownermanager and the successor are members of the family, the quality of their relationship will directly reflect the overall quality of family ties. We hypothesize that family cohesion and adaptability will be positively associated with the quality of the owner-manager and successor relationship.

More specifically, we believe that the collectivist orientation characterizing highly cohesive families will foster in both owner-manager and successor an awareness of the ways in which their goals are aligned and will promote a higher degree of empathy. This would, in turn, help them to define succession as being important not just to themselves, but to the entire family. We also believe that because families high on cohesion tend to stick together during times of distress (Olson, 1988), family members would help the ownermanager and the successor cope with the stress associated with the leadership transition. Finally, high cohesion also suggests that the family is capable of recognizing and maintaining clear boundaries between subsystems (for example, between parents and children) and between the family and the business (Olson, 1988; Rosenblatt, de Mik, Anderson, \& Johnson, 1985). Maintaining clear boundaries minimizes the likelihood that family problems and strains will be inappropriately brought into the workplace and into the relationship between the owner-manager and the successor.

HYPOTHESIS 1: Family cohesion will be positively associated with the quality of the relationship between the owner-manager and the successor.

We also hypothesize that the quality of the relationship between the owner-manager and the successor will be contingent on family adaptability. We believe that highly adaptable families are more likely to help the owner- 
manager and the successor adjust to the changes that succession imposes. For example, as the transition unfolds, authority for business decisions that affect family welfare shifts from the owner-manager to the successor. As the dependency of family members shifts from the owner-manager to the successor, parental and sibling relationships need to be realigned. The better able a family is to adapt to this transition, the more likely it is to be supportive of the relationship between the owner-manager and the successor. In addition, highly adaptive families enhance the ability of members to think independently and understand the differences between each individual's expectations and needspsychological differentiation (Bowen, 1978). This, in turn, enhances the ability of the owner-manager and successor to communicate.

HYPOTHESIS 2: Family adaptability will be positively associated with the quality of the relationship between the owner-manager and the successor.

\section{Effect of Family Cohesion and Adaptability on the Degree of Commit-} ment to the Business. The degree of family cohesion and adaptability are also hypothesized to directly and positively affect the family's commitment to the business. With greater cohesion comes increased loyalty to the family and a belief that its members share responsibility for perpetuating and enhancing family assets. In highly cohesive families, parents devote considerable time to discussing their expectations about the future with their children (Olson, 1988). This, combined with a strong sense of family loyalty, fosters the desire in the younger generation to participate in parental dreams about the continuation of the business in the family. We believe that in these families, children are encouraged to play a role in important family decisions, including the choice of successor. Family involvement in decision making enhances the younger generations' sense of control over the destiny of the company and increases their commitment to it.

HYPOTHESIS 3: Family cohesion will be positively associated with the family's commitment to the firm.

It was also expected that family adaptability would affect the degree of family commitment to the business. As previously stated, families that are highly adaptable encourage their members to differentiate and develop their own personal visions of the ways in which the family company will further their individual as well as family needs. These personal visions, in turn, enhance commitment and enthusiasm for the company and its future. In addition, in adaptable families, members are capable of negotiating their individual expectations in order to develop a shared vision of the company to which the entire family can become committed. Adaptable families also encourage the sharing of leadership responsibilities (Olson, 1988), which, we believe, 
increases the desire of members to become involved with decisions that determine the fate of the company.

HYPOTHESIS 4: Family adaptability will be positively associated with the family's commitment to the firm.

Next we shall turn our attention to how the mediating variables, family commitment and the owner-manager and successor relationship, influence succession planning and the training of the successor.

Relationship of Family Commitment to the Business to Succession Planning and Successor Training. Succession planning is difficult to initiate in family companies because families tend to resist addressing the consequences of generational change, including the inevitability of parental death, the transfer of authority from the senior to the younger generation, and the acknowledgment that some siblings may be better equipped than others to run the company (Lansberg, 1988; Ward, 1987; Handler \& Kram, 1988). For a family to overcome these resistances, family members must be clear about the benefits of the company's continuity. Highly committed families are clear about the positive link between the longevity of the business and the well-being of the family. As a result, they view succession planning not only as a specific set of managerial tasks, but as an activity that must be done for the greater good of the family.

Family commitment is particularly critical to the owner-manager, whose direct involvement with the planning process is necessary. We believe that in a high-commitment family, the owner-manager knows that there are heirs who are interested in the perpetuation of the company and, knowing that succession is possible, is more likely to plan for it. Further, highly committed families are likely to provide the owner-manager and successor with emotional support during the transition, thus making planning less stressful.

HYPOTHESIS 5: The family's commitment to the business will be positively associated with the extent of succession planning.

We hypothesize that the degree of family commitment to the company also will influence whether or not a successor is developed and trained. As is the case with succession planning, it was believed that families that are highly committed to their firms would view the development of competent senior managers and, in particular, of a successor, as critical to ensuring the future security and growth of their assets. We also reasoned that the owner-manager and the successor, as well as other key nonfamily managers, would be more likely to engage in the training process if there were strong family commitment to the business.

The family's commitment to the business is also likely to affect the successor's view of the training process. We reasoned that successors from families committed to their firms would view business training as a vehicle through which to earn the respect of family members. 
HYPOTHESIS 6: The family's commitment to the business will be positively associated with the degree of successor training.

Influence of the Quality of Owner-Manager-Successor Relationship on Successor Training. We hypothesize that the quality of the relationship between the owner-manager and the successor would affect the degree to which the successor would be trained to take over the owner-manager's responsibilities. Training necessitates that the owner-manager and the successor acknowledge that they have things to learn from one another. For the owner-manager, this means a willingness to take pride in and appreciate the successor's potential and achievements. It also requires that the ownermanager have the flexibility to explore and accept new approaches to managerial work and have the interest to help design a meaningful training program. For the successor, it means appreciating the accumulated wisdom of the owner-manager and his or her contributions to the business. It also necessitates that the successor not reject work methods established by the ownermanager without carefully assessing their value to the business.

Differentiation, which is a component of an effective owner-managersuccessor relationship, is also an integral element of effective leadership training (Alderfer, 1988). Such training necessitates conveying to the successor the importance of making decisions that neither imitate nor reactively negate the views held by the owner-manager. Differentiation, in short, enables a successor to establish an internal sense of authority (Bowen, 1978).

Effective training also requires that the owner-manager and the successor not feel threatened by the fact that the training process paves the way for the owner-manager's departure. A high-quality relationship between the ownermanager and the successor helps them to constructively address the attitudes and feelings evoked by the owner-manager's imminent exit (Astrachan, 1990; Sonnenfeld, 1988).

As stated above, senior nonfamily managers often play a critical role in the mentoring and training of the successor (Dyer, 1989). However, if the relationship between the owner-manager and the successor is troubled, it is unlikely that these managers would want to be involved with training. Under such conditions, involvement with the training of the successor may be viewed as a betrayal of the owner-manager and is therefore likely to be avoided. In addition, if the owner-manager's relationship with the successor is troubled, nonfamily managers are likely to doubt the owner-manager's commitment to the choice of successor and hence view training as being of no consequence.

HYPOTHESIS 7: The quality of the relationship between the owner-manager and the successor will be positively associated with the extent of successor training.

Hypotheses 1 through 7 represent a behavioral model of the influence of family relationships on succession planning and successor training. Effective 
family relationships were predicted to increase the likelihood of succession planning and successor training, not directly but indirectly, by increasing the level of family commitment to the firm and the quality of the owner-manager and the successor relationship. While others have suggested that family relationships, in general, influence succession planning, no prior theory has specified the mediating effect of the family's commitment to the firm and of the quality of the relationship between the owner-manager and the successor.

\section{Methodology}

The following methodology section discusses the procedures used in the study, the participants, the measures used, definition of variables, and method of analysis.

Procedure. The data were collected during 1986 and 1987 from a sample of 300 family businesses drawn randomly from the membership roles of two national retail organizations. One was a dealership network of a large U.S. automobile manufacturer, and the other was an industry association. Because the focus of this study was the impact of family relationships on succession variables, we deliberately chose to sample family firms within specific industries in an attempt to reduce the impact of environmental variability on the results.

Participants. All of the people surveyed were either owner-managers or successors. We chose to focus the study on the perspective of the owner-manager and the successor because ownership, family, and management responsibilities are generally transferred from the owner-manager to the successor, making these two actors pivotal to the succession process. While the views of other actors are also important, their inclusion was beyond the scope of this research. Companies were selected for the study because they had either partially or totally completed the transfer of ownership and management responsibilities. While successors surveyed here differ in many ways, each had been identified as the next-generation leader of the firm and had begun the transition into that role.

Of the 300 firms surveyed, completed questionnaires were returned from 109 firms (36 percent). Out of the 109 firms that responded, 21 firms (19 percent) returned questionnaires from both the owner-manager and the successor, 25 firms ( 23 percent) returned a questionnaire from the owner-manager only, and 63 firms (58 percent) returned a questionnaire from the successor only. In total, questionnaires were received from eighty-four successors and forty-six owner-managers. Telephone follow-up interviews with the participating firms revealed that in approximately one-half (29) of the firms in which only the successor responded, the owner-manager was unavailable because he had either died, become incapacitated, or had retired and moved away. In approximately 25 percent (23) of the firms where only the successor or the owner-manager returned a completed questionnaire, it was found that the receiving party withheld the instrument from the other family business mem- 
ber in the belief that it would trouble the other person, or because of an unwillingness to discuss issues covered in the questionnaire with the other person. While this response rate may seem low, we believe it is consistent with the strong norms of privacy held by family businesses (Wortman, 1992) and also can be explained by the differences in degree to which the succession transition had been completed (see age-range data in next paragraph).

Among the 109 responding firms, the company's founding year ranged from 1906 to 1976 (the average founding year was 1945), annual sales ranged from $\$ 400,000$ to $\$ 30$ million (average annual sales were $\$ 13$ million), and the number of employees ranged from 7 to 100 (the average number of employees was 31) at the time the survey was taken. The percentage of the company owned by the owner-manager and his family ranged from 43 percent to 100 percent ( 56 percent of all the firms studied were owned entirely by the owner-manager and his nuclear family). All of the participants were white males. The ages of owner-managers ranged from 44 to 86 (the average age for the owner-managers was 63). The age of the successors ranged from 25 to 56 (the average age for successors was 40).

Measures. The instrument used in this study was a 131-item questionnaire consisting of two sections. One focused on family business succession behaviors (95 items) covering a range of topics, including those focused on in this article. These items were derived from an inductive study of twenty family companies in which both owner-managers and successors were interviewed at length about their succession experiences (Lansberg, 1985). The second section measured family relationships using 36 items adapted from the FACES questionnaire developed and extensively tested by Olson and his colleagues (1988). For each item, participants indicated the accuracy with which it described their family business situation using a six-point rating scale varying from "very inaccurate" to "very accurate" (questionnaire items used for this study are reproduced fully in the Appendix to this chapter).

The instructions to the questionnaire included definitions for the following terms: succession, successor, owner-manager, and family. All of these definitions are consistent with the use of these terms throughout this article. The order of the items in each of the two sections of the questionnaire were randomized to reduce interitem response effects.

Independent Variables: Family Relationships. Despite the self-report nature of the family items used in this instrument, the FACES questionnaire is one of the few statistically reliable and valid measures of family behavior available (Olson et al., 1988; Olson, 1986; Green, Kolevzon, \& Vosler, 1985). The scale measuring family cohesion (Cronbach alpha $=.89$ ) used in this study included twelve items adapted from the FACES questionnaire (see Appendix). The scale measuring family adaptability (Cronbach alpha $=.77$ ) was composed of six items (see Appendix).

Mediating Variables. Family commitment to the business was measured by a scale (Cronbach alpha $=.70)$ composed of three items (see Appendix). The 
owner-manager-successor relationship scale (Cronbach alpha $=.78$ ) was composed of six items (see Appendix).

Control Variable: Owner-Manager and Successor Differences. We expected that the relationship between the variables in our model would be systematically affected by the common tendency for hierarchical relations to be viewed more positively by superiors than by subordinates (Vroom, 1981). In their work on the relationship between fathers and sons who work together in family companies, Davis and Tagiuri (1989) also found evidence for this bias. However, the study was designed to statistically control for the effect of the respondent's role being either that of the owner-manager or the successor. This variable was measured as a binomial item that asked respondents their role (either ownermanager or successor).

Dependent Variables: Succession Planning and Successor Training. Succession planning was measured by a scale (Cronbach alpha $=.70$ ) consisting of two items (see Appendix). Successor training was measured by a scale (Cronbach alpha $=.60$ ) consisting of three items (see Appendix).

Minimum values, maximum values, means, standard deviations, and Pearson correlation coefficients of the scales are shown in Table 1.

Analysis. All hypotheses were tested using multiple regression analysis. In total, three regression models were used. All analyses used type IV sums of squares (last-in method), because this approach determines the independent effects of all variables in the model and is, therefore, most conservative.

Model 1 was used to test whether family cohesion and adaptability-our independent variables - are positively associated with family commitment to the firm and the quality of the relationship between the owner-manager and the successor-our mediating variables. More specificially, Hypotheses 1 through 4 were tested using Model 1:

$$
F, R=\beta_{0}+S+C+A+e
$$

where $F$ and $R$ are the mediating variables ( $F$ stands for family commitment to the firm, and $R$ represents the quality of the owner-manager and successor relationship), $\beta_{0}$ is the intercept, $S$ is a binomial dummy variable controlling for the respondent's role as either owner-manager or successor, $C$ refers to family cohesion, $A$ represents family adaptability, and $e$ is the error term.

Model 2 tested whether family commitment to the business and the quality of the owner-manager and successor relationship-our mediating variables-are positively associated with succession planning and successor training-our dependent variables. More specifically, Hypotheses 5 through 7 are tested using Model 2:

$$
P, T=\beta_{0}+S+F+R+e
$$

where $P$ and $T$ represent the dependent variables ( $P$ stands for succession planning, and $T$ represents successor training). 


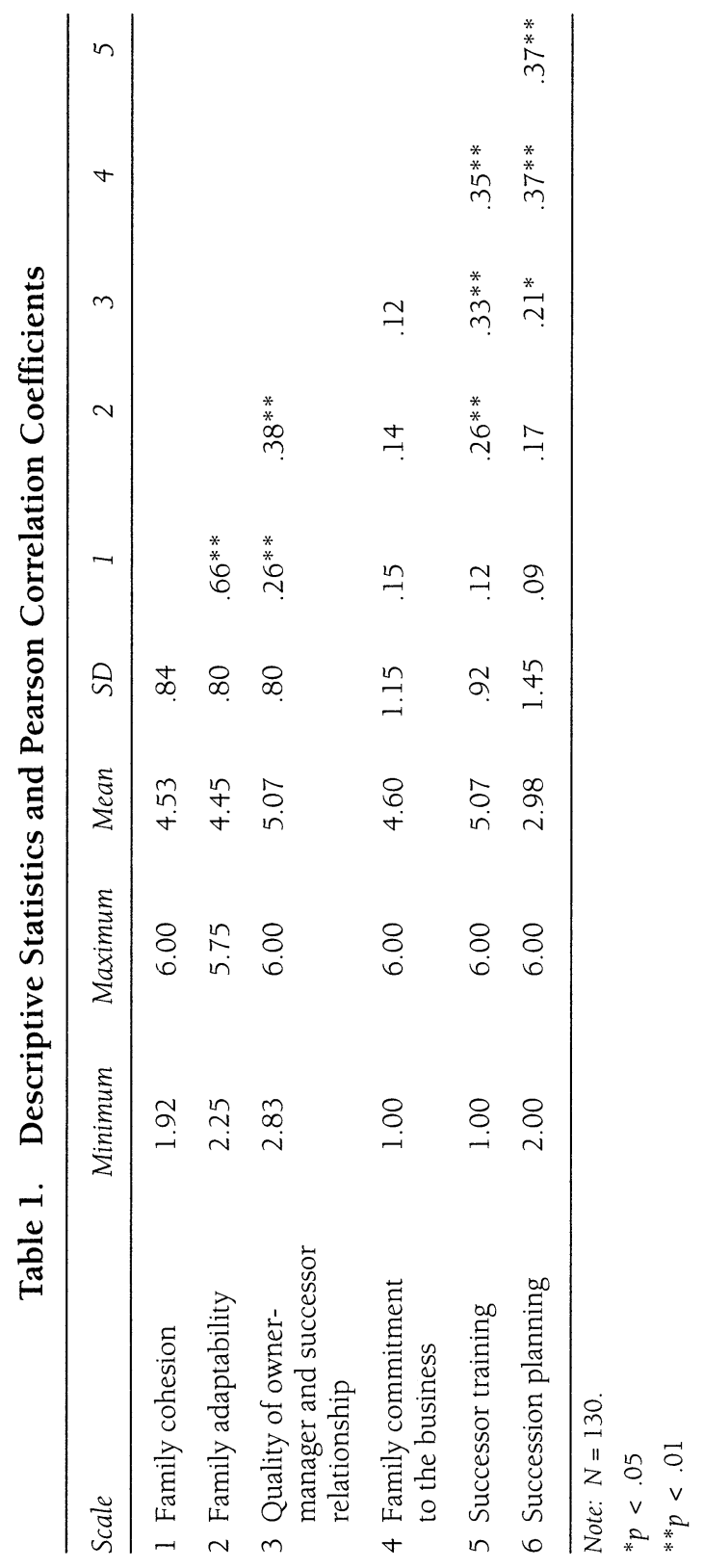


Model 3 was used to test whether family cohesion and adaptability had a direct influence on succession planning and successor training. More specifically, Model 3 was designed to assess the extent to which family commitment to the business and the quality of the owner-manager and successor relationship serve to actually mediate the effect of family adaptability and cohesionour independent variables - on succession planning and successor trainingour dependent variables:

$$
P, T=\beta_{0}+S+F+R+C+A+e
$$

\section{Results}

The hypothesized relationships between the independent and mediating variables were tested using Model 1. Table 2 presents the estimates of these models. Model 1 tested the relationship of family cohesion and adaptability to the quality of the relationship between the owner-manager and successor and to the family's commitment to the firm.

Hypothesis 1 predicted that family cohesion would be positively associated with the quality of the owner-manager and successor relationship for both owner-managers and successors. This hypothesis was not supported by Model 1. No statistically significant main effects were found. However, a separate test performed for owner-managers showed that family cohesion is related to the quality of the owner-manager and successor relationship.

Hypothesis 2 postulated that family adaptability would be positively related to the quality of the owner-manager and successor relationship. This hypothesis was supported by Model 1 . There was a statistically significant main effect for adaptability on the quality of the owner-manager and successor relationship (estimate for adaptability was .38 and was significant at $p<.01$ ).

Our third hypothesis predicted that family cohesion would be positively associated with the family's commitment to the firm. This relationship was supported by Model 1. A statistically significant main effect was found for cohesion on family commitment to the firm (estimate for cohesion was .18 and was significant at $p<.05)$. However, these results should be interpreted cautiously, as the overall $F$ ratio for the model did not attain significance at the .05 level.

Hypothesis 4 proposed that family adaptability would be positively associated with the family's commitment to the firm for both owner-managers and successors. No evidence was found for this relationship in Model l. Again, this result should be interpreted with caution due to the lack of significance of the $F$ ratio for the overall model.

Hypotheses 5 through 7 concerned the relationship between the mediating variables and the dependent variables. These relationships were tested using Models 2 and 3. The estimates for these models are shown in Table 3. Model 2 examined the direct effect of the family's commitment to the business and the quality of the relationship between the owner-manager and the successor on 
Table 2. General Linear Model Estimates of Family Relationship Influence on Mediating Factors Model

\begin{tabular}{lccc}
\hline & \multicolumn{3}{c}{ Main Effects } \\
\cline { 2 - 5 } Independent Variables & $\begin{array}{c}\text { Quality of Owner-Manager and } \\
\text { Successor Relationship }\end{array}$ & $\begin{array}{c}\text { Family Commitment } \\
\text { to the Business }\end{array}$ \\
\hline Intercept & $3.29 *(0.45)$ & $3.33^{*}(0.66)$ \\
Respondent's role (owner- & $.06(0.17)$ & $-.28 \quad(0.24)$ \\
manager or successor) $(S)$ & $.02 \quad(0.11)$ & $.18 \quad(0.16)$ \\
Family cohesion $(C)$ & $.38^{*}(0.12)$ & $.11 \quad(0.18)$ \\
Family adaptability $(A)$ & 5.87 & 1.62 \\
F ratio & .15 & .06 \\
$R^{2}$ & & &
\end{tabular}

Note: Standard errors in parentheses; $N=130$.

${ }^{*} p / f<.01$

Table 3. General Linear Model Estimates of Mediating Factors Influences on Succession Models

\begin{tabular}{|c|c|c|c|c|}
\hline \multirow[b]{3}{*}{ Independent Variables } & \multicolumn{4}{|c|}{ Main Effects } \\
\hline & \multicolumn{2}{|c|}{ Succession Planning } & \multicolumn{2}{|c|}{ Succession Training } \\
\hline & Model 2 & Model 3 & Model 2 & Model 3 \\
\hline Intercept & $-0.47(0.91)$ & $-0.31(1.04)$ & $2.21 * *(0.56)$ & $2.19 * *(0.62)$ \\
\hline $\begin{array}{l}\text { Respondent's role } \\
\text { (owner-manager } \\
\text { or successor) (S) }\end{array}$ & $.48(0.27)$ & $.42(0.30)$ & $.06(0.17)$ & $.01(0.18)$ \\
\hline Family cohesion $(C)$ & & $-.15(0.21)$ & & $-.13(0.12)$ \\
\hline Family adaptability $(A)$ & & $.21(0.24)$ & & $.20(0.14)$ \\
\hline $\begin{array}{l}\text { Quality of owner- } \\
\text { manager and successor } \\
\text { relationship }(R)\end{array}$ & $.28(-0.16)$ & $.23(0.18)$ & $.34 * *(0.10)$ & $.31 * *(0.11)$ \\
\hline $\begin{array}{l}\text { Family commitment to } \\
\text { the business }(F)\end{array}$ & $7.41 * *(0.11)$ & $.38 * *(0.12)$ & $.25 * *(0.07)$ & $.22 * *(0.07)$ \\
\hline$F=$ ratio & $7.54 * *$ & $2.42 *$ & $9.76^{* *}$ & $5.89 * *$ \\
\hline$R^{2}$ & .18 & .17 & .21 & .23 \\
\hline
\end{tabular}

Note: Standard errors in parentheses; $N=130$.

${ }^{*} p / f<.05$

${ }^{* *} p / f<.01$ 
succession planning and successor training. Model 3 is identical to Model 2, except that it also tests for the independent effects of family adaptability and family cohesion on the dependent variables succession planning and successor training. The inclusion of family adaptability and family cohesion allows us to exaine whether these independent family relationship variables affect the relationship between the mediating and dependent business outcome variables, and whether there are any direct effects between family relationships and business outcomes.

Hypothesis 5 predicted that the family's commitment to the business would be positively associated with the extent of succession planning. This relationship was supported by Model 2 . There was a statistically significant main effect for family commitment on succession planning (estimate for commitment was .41 and was significant at $p<.01$ ). Model 3 confirms that the relationship between family commitment and succession planning holds when the independent variables, family cohesion and family adaptability, are introduced into the model. There was a statistically significant main effect for family commitment on succession planning and no significant effects for family cohesion and family adaptability (estimate for commitment was .38, and was significant at $p<.01$ ).

Hypothesis 6 postulated that the family's commitment to the firm would be positively associated with the degree of successor training. This relationship was supported by Model 2 . There was a statistically significant main effect for family commitment to the business on successor training (estimate for commitment was .25 and was significant at $p<.01$ ). Model 3 confirms that the relationship between family commitment to the business and successor training holds when the independent variables are introduced into the model. There was a statistically significant main effect for family commitment to the business on successor training and no significant effects for family cohesion and family adapatability (estimate for commitment was .22 and was significant at $p<.01$ ).

Finally, Hypothesis 7 posited that the quality of the relationship between the owner-manager and the successor would be positively associated with the degree of successor training. This relationship was supported by Model 2 . There was a statistically significant main effect for the quality of the ownermanager and successor relationship on successor training (estimate for relationship was .34 and was significant at $p<.01$ ). Model 3 confirms that the relationship between successor training and the quality of the owner-manager and successor relationship to the business holds when the independent variables are introduced into the model. There was a statistically significant main effect for the quality of the owner-manager and successor relationship on successor training and no significant effects for family cohesion and family adaptability (estimate for relationship was .31 and was significant at $p<.01$ ).

\section{Discussion}

Researchers have recently begun to empirically investigate direct links between family relationships and administrative behavior in family businesses (Davis 
\& Tagiuri, 1989; Malone, 1989). Prior research has yielded mixed results, suggesting that the effect of family relationships on managerial behavior may be mediated by a number of factors. Empirical research that tries to statistically explore direct and indirect effects of family relationships on organizational behavior has been lacking (Hollander \& Elman, 1988). The results presented here substantiate the importance of factors that mediate the influence of family relationships on administrative variables.

Specifically, these results show that family commitment to the business acts as a mediator of the influence of family cohesion on both succession planning and successor training. The study also revealed that the quality of the ownermanager and successor relationship mediates the influence of both family cohesion and adaptability on successor training. These findings support the structural model underlying Hypotheses 1, 2, 3, 5, 6, and 7. It is important to emphasize that family cohesion and adaptability did not directly affect the dependent variables succession planning and successor training. This suggests that in family businesses, the impact of family relationships on organizational behavior cannot be fully discerned without accounting for mediating factors.

An important revision to the model presented here concerns the fact that family adaptability was not associated with the degree of family commitment to the firm. Contrary to Hypothesis 4 , it may be that family rigidity rather than flexibility, is associated with family commitment to the business. Ownermanagers may view a high level of family adaptability as an indication of personal disloyalty and a low commitment to the firm. It is also possible that there exists a complex interaction between cohesion and adaptability. For example, it may be that adaptability only affects commitment in families that are either high or low on cohesiveness.

In drawing conclusions from these results we must be careful to recognize the potential impact of other issues not considered in our model. Of particular importance is the notion that the relationship between family and organizational factors in a family business is often reciprocal (Miller \& Rice, 1967). Perhaps certain organizational factors have an impact on the degree of family adaptability and cohesion. For example, a downturn in business performance may increase cohesion in the proprietary family as members pull together to cope with increased stress. In addition, future research should explore how business issues influence family relationships.

A number of methodological factors may limit the conclusions that can be drawn from this research. First, some firms in the sample contributed responses from both the owner-manager and successor, while other companies only provided questionnaires from either the owner-manager or the successor. This poses the problem that those responses coming from the same firm would not be independent, potentially biasing the sample in the direction of the overrepresented firms. Post hoc tests yielded no significant effects for the influence of the company when a term for the respondent's firm was included as a main effect and as an interaction effect in all of the models. Further, this analysis did not alter the statistical significance of any of the findings reported here. Future 
studies should seek to gather complete data from owner-managers and successors, as well as other family members.

Another potential bias in the data is that all of the firms sampled had a designated successor. None had a succeeding team of leaders. While there was considerable variance among the firms sampled in terms of the degree of succession planning and successor training, by selecting only firms in which there was a designated successor, those firms in which there was no planning and training were excluded again, limiting the population to which these findings can be generalized.

The fact that this study relies on individual self-reports is another important limitation. While we have confidence in the extensively tested family cohesion and adaptability measures derived from the FACES instrument, the other measures may be open to question. Further research that relies on multiple methodologies will help to substantiate the validity of the measures used in this study. Again, the validity and reliability of the findings of this study would also be enhanced by including the perspectives of people who occupy other roles in the family business. The perspective of individuals in family businesses are likely to vary systematically depending on whether they are involved with business ownership, management, or family (Lansberg, 1988; Davis $\&$ Tagiuri, 1986). For example, people in the family who are not in the business are likely to attribute more importance to family factors in determining succession planning and successor training than would people not in the family. Conversely, nonfamily employees may view organizational rather than family factors as being paramount to the succession transition.

A final limitation concerns the nature of the businesses included in this study. The sample was drawn from only two industries, both of which concern retail trade. By selecting these firms, environmental forces were held constant, thus increasing internal validity. However, the generalizability of these findings potentially was thereby compromised.

Despite these qualifications, this study underscores that family relationships do play an important role in determining the extent of succession planning and successor training in a family business. This study highlights the importance of looking at the specific and complex relations between family and business variables. Further, this study underscores the role of factors that mediate the relations between family and business. Future research on family businesses will benefit from further investigations of the intricate interactions that may exist between specific family and administrative variables.

\section{Appendix: Questionnaire Items}

Family Cohesion Scale Items

1. It is easier for family members to discuss problems with people outside the family than with each other.

2. There are frequent family gatherings. 
3. Children in the family are loved equally.

4. Family members know each other's close friends.

5. Family members have difficulty thinking of things to do together.

6. Family members feel closer to people outside the family than to each other.

7. Family members go along with what the family decides to do.

8. Family members like to spend their free time with each other.

9. Family members avoid each other.

10. Family members share interests and hobbies.

11. The family does things together.

12. In the family, everyone goes his or her own way.

Family Adaptability Scale Items

1. It's easy for all family members to express their opinions.

2. Each family member has input into major family decisions.

3. Family members discuss problems and feel good about the solutions.

4. The family tries new ways of dealing with problems.

5. The family is flexible about sharing responsibilities.

6. Family members are afraid to speak their minds to each other.

Owner-Manager and Successor Relationship Scale Items

1. The owner-manager and successor have a trusting, warm, and mutually supportive relationship.

2. The successor readily acknowledges the owner-manager's achievements.

3. It is easy for the owner-manager and the successor to express their opinions to each other.

4. The owner-manager and the successor are flexible in how they handle their differences.

5. The owner-manager readily acknowledges the successor's achievements.

6. The owner-manager allows the successor to learn from his or her own mistakes.

Family Commitment to the Business Scale Items

1. The owner-manager wants his or her children to enter the business.

2. The owner-manager is deeply committed to the business continuing as a family legacy.

3. Had the successor not joined the family firm, family members would have been very disappointed.

Succession Planning Scale Items

1. Succession has not been explicitly planned in the family firm. 
2. Explicit selection criteria have been developed for identifying the best successor.

\section{Successor Training Scale}

1. The owner-manager has played an active part in training and coaching the successor.

2. The successor worked his or her way up in the firm.

3. The successor has been specifically trained to take over management of the firm.

\section{References}

Alderfer, C. P. (1988). Teaching personality and leadership. Organizational Behavior Teaching Review, 12, 12-33.

Astrachan, J. H. (1988). Family firm and community culture. Family Business Review, 1, 165-189.

Astrachan, J. H. (1990). Mergers, acquistions, and employee anxiety: A study of separation anxiety in a corporate context. New York: Praeger.

Astrachan, J. H., \& Astrachan, B. M. (1993). Family business: The challenges and opportunities of interprofessional collaboration. Working paper, Kennesaw State College School of Business Administration, Marietta, GA.

Beckhard, R., \& Dyer, W. G., Jr. (1983, Summer). Managing continuity in the family-owned business. Organizational Dynamics, 5-12.

Bowen, M. (1978). Family therapy in clinical practice. New York: Aronson.

Christensen, C. R. (1953). Management succession in small and growing enterprises. Boston: Harvard University, Graduate School of Business Administration.

Correll, R. W. (1989). Facing up to moving forward: A third-generation successor's reflections. Family Business Review, 2, 17-30.

d'Amboise, G., \& Muldowney, M. (1988). Management theory for small businesses: Attempts and requirements. Academy of Management Review, 13, 226-240.

Davis, J. A., \& Tagiuri, R. (1986). Bivalent attributes of the family firm. Unpublished manuscript, University of Southern California, Los Angeles.

Davis, J. A., \& Tagiuri, R. (1989). The influence of life stage on father son work relationships in family companies. Family Business Review, 2, 47-77.

Davis, P., \& Stern, D. (1980). Adaptation, survival, and growth of the family business: An integrative business perspective. Human Relations, 30, 207-224.

Donnelly, R. (1964, July-August). The family business. Harvard Business Review.

Dyer, W. G., Jr. (1986). Cultural change in family firms: Anticipating and managing business and family transitions. San Francisco: Jossey-Bass.

Dyer, W. G., Jr. (1989). Integrating professional management into a family owned business. Family Business Review, 2, 221-236.

Friedman, S. (1991). Sibling relationships and intergenerational succession in family firms. Family Business Review, 1, 3-21.

Green, R. J., Kolevzon, M. S., \& Vosler, N. R. (1985). The Beavers-Timberlawn model of family competence and the circumplex model of family adaptability and cohesion: Separate but equal? Family Process, 24, 385-398.

Greiner, L. E. (1972, July-August). Evolution and revolution as organizations grow. Harvard Business Review, 37-46.

Handler, W., \& Kram, K. (1988). Succession in family firms: The problem of resistance. Family Business Review, 1, 361-383. 
Hershon, S. A. (1975). The problem of management succession in family business. Unpublished doctoral dissertation, Harvard Graduate School of Business Administration, Cambridge, MA.

Hollander, B. S., \& Elman, N. S. (1988). Family owned businesses: An emerging field of inquiry. Family Business Review, 1, 145-164.

Kepner, E. (1983). The family and the firm: A coevolutionary perspective. Organizational Dynamics, 12, 57-70.

Lansberg, I. (1985). Family firms that survive their founders. Paper presented at the annual meeting of the Academy of Management, San Diego.

Lansberg, I. (1988). The succession conspiracy. Family Business Review, 1, 119-143.

Malone, S. (1989). Selected correlates of business continuity planning in the family business. Family Business Review, 2, 341-355.

Miller, E. J., \& Rice, A. K. (1967). The family business in contemporary society. In E. J. Miller $\&$ A. K. Rice (Eds.). Systems of organization. London: Tavistock.

Olson, D. H. (1986). Circumplex model: Validation studies and FACES III. Family Process, 25, 337-351.

Olson, D. H. (1988). The circumplex model of family systems VIII: Family assessment and intervention. In D. H. Olson, C. S. Russell, \& D. H. Sprenkle (Eds.). The circumplex model: Systemic assessment and treatment of families. New York: Haworth.

Olson, D. H., Russell, C. S., \& Sprenkle, D. H. (Eds.). (1988). The circumplex model: Systemic assessment and treatment of families. New York: Haworth.

Poza, E. J. (1989). Smart growth: Critical choices for business continuity and prosperity. San Francisco: Jossey-Bass.

Rosenblatt, P. C., de Mik, L., Anderson, R. M., \& Johnson, P. A. (1985). The family in business. San Francisco: Jossey-Bass.

Schein, E. H. (1985). Organizational culture and leadership. San Francisco: Jossey-Bass.

Smith, K. K. (1989). The movement of conflict in organizations: The joint dynamics of splitting and triangulation. Administrative Science Quarterly, 34, 1-20.

Sonnenfeld, J. (1988). The heroes' farewell: What happens when CEOs retire. Oxford: Oxford University Press.

Trow, D. B. (1961). Executive succession in small companies. Administrative Science Quarterly, 6, 228-239.

Vroom, V. H. (1981). Reflections on leadership. Paper presented at the Division 14 Presidential Address, American Psychological Association Annual Meeting, Los Angeles.

Ward, J. L. (1987). Keeping the family business healthy: How to plan for continuing growth, profitability and family leadership. San Francisco: Jossey-Bass.

Woehrer, C. E. (1988). Ethnic families in the circumplex model: Integrating nuclear and extended family systems. In D. H. Olson, C. S. Russell, \& D. H. Sprenkle (Eds.). The circumplex model: Systemic assessment and treatment of families. New York: Haworth.

Wortman, M., Jr. (1992). Typology of family firm strategies: A reprise from strategic management. Paper presented at the Second International Symposium on Family and Closely-Held Business, John E. Anderson Graduate School of Management, University of California, Los Angeles.

Zeitlin, M. (1976). Corporate ownership and control. American Journal of Sociology, 79, 10731119.

Ivan Lansberg is principal, Lansberg Associates, a research and consultation firm specializing in family business, in New Haven, Connecticut, and is the previous editor of Family Business Review.

Joseph $H$. Astrachan is associate professor of family business and management, Michael J. Coles School of Business, Kennesaw State College, Marietta, Georgia. 